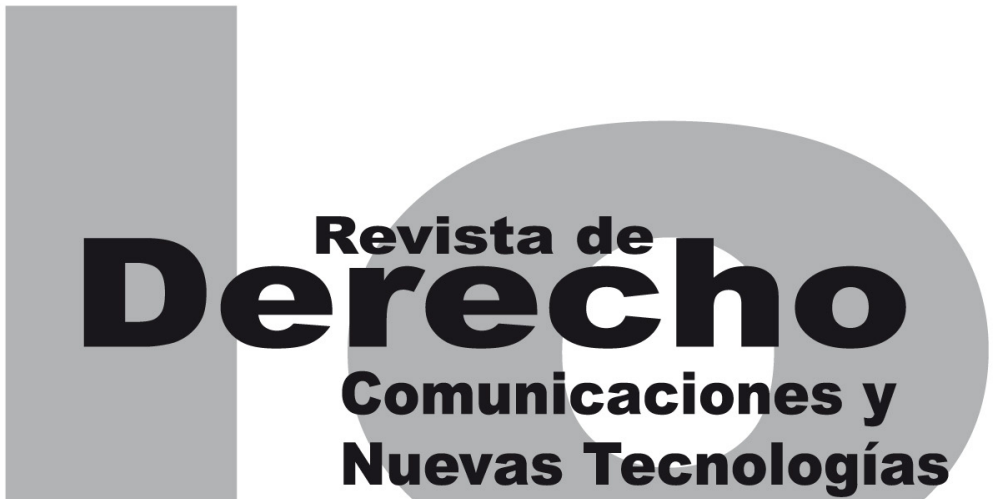

EL DEBER DE INFORMACIÓN EN LA RESPONSABILIDAD POR PRODUCTOS DEFECTUOSOS.

EL ARTÍCULO 19 DEL ESTATUTO DEL CONSUMIDOR COLOMBIANO

FERNANDO ANDRÉS PICO ZÚÑIGA

Artículo de reflexión

DOI: http://dx.doi.org/10.15425/redecom.15.2016.05

Universidad de los Andes

Facultad de Derecho

Rev. derecho comun. nuevas tecnol. No. 15

enero - junio de 2016. e-ISSN 1909-7786 


\title{
El deber de información en la responsabilidad por productos defectuosos. El artículo 19 del Estatuto del Consumidor Colombiano
}

\section{Resumen}

El artículo 19 de la Ley 1480 de 2011 -Estatuto del Consumidor - introdujo en nuestro ámbito el deber administrativo de información por parte de los miembros de la cadena de producción, distribución y comercialización que conozcan del defecto de alguno de sus productos. Al amparo de dicha normativa, muchos son los interrogantes que desde el plano teórico y práctico surgen: ¿Qué se debe informar?, ¿Qué y cuáles son las denominadas medidas correctivas que se deben tomar?, ¿Cómo juega el deber de información del artículo 19 ante la obligación indemnizatoria de la responsabilidad por productos defectuosos?, ¿Cuáles son las sanciones ante el incumplimiento del deber? El presente documento pretende, bajo el análisis teórico del artículo 19 del Estatuto, resolver los citados cuestionamientos. Más aún, a la luz de la filosofía y entendimiento del artículo 19 del Estatuto del Consumidor, se busca ofrecer algunas ideas para la regulación del precepto a propósito de esclarecer sus implicaciones en la relación de consumo, la responsabilidad por productos defectuosos y frente a la autoridad administrativa.

Palabras clave: principio de la buena fe, buena fe objetiva, deber de información, deber de evitar el daño, deber de mitigar el daño, product recall, alterum non laedere, responsabilidad por productos defectuosos, Estatuto del Consumidor colombiano.

\section{The duty of information in the product liability. Article 19 of Colombian Consumer Law}

\begin{abstract}
Article 19 of Colombian Law 1480 of 2011 introduces the administrative duty of information by the producers, dealers or marketers who know the defect of one of its products in order to protect the rights of the Colombian users. However, the newest rule in Colombia it is not clear at all. The regulation announces hard riddles to solve: What to report to the administration? What are the corrective measures to have to be taken by the producers, dealers or marketers when find a defect in their products? How article 19 it is related to product liability? Which are the penalties for non-compliance? Those, essentially, are the problems that this paper is focused on. Further, with that goal, this document suggests ideas for the regulation of article 19 and clarify the impact of the rule on product liability and the role of the administration in this scenario.
\end{abstract}

Key words: Good faith, duty of information, duty to avoid damage, duty to mitigate the damage, product recall, product liability, Colombian Law 1480 of 2011.

\section{0 dever de informação na responsabilidade por produtos defeituosos. 0 artigo 19 do Estatuto do Consumidor Colombiano}

\section{Resumo}

O artigo 19 da Lei 1480 de 2011 -Estatuto do Consumidor-, introduziu em nosso âmbito o dever de informação, primordialmente administrativo, por parte dos membros da cadeia de produção, distribuição e comercialização que conheçam o defeito de algum de seus produtos. Ao amparo de dita normativa, muitos são os interrogantes que desde o plano teórico e prático surgem: 0 que se deve informar? 0 que e quais são as denominadas medidas corretivas que se devem tomar? Como joga o dever de informação do artigo 19 ante a obrigação indenizatória da responsabilidade por produtos defeituosos? Quais são as sanções ante o incumprimento do dever? 0 presente documento pretende, sob a análise teórica do artigo 19 do Estatuto, resolver os citados questionamentos. Além disso, à luz da filosofia e entendimento do artigo 19 do Estatuto do Consumidor, se busca oferecer algumas ideias para a regulação do preceito a propósito de esclarecer suas implicações na relação de consumo, a responsabilidade por produtos defeituosos e frente à autoridade administrativa.

Palavras-chave: princípio da boa fé, boa fé objetiva, dever de informação, dever de evitar o dano, dever de mitigar o dano, product recall, alterum non laedere, responsabilidade por produtos defeituosos, Estatuto do Consumidor colombiano. 


\title{
El deber de información en la responsabilidad por productos defectuosos. \\ El artículo 19 del Estatuto del Consumidor Colombiano ${ }^{\star 1}$
}

\author{
FERNANDO ANDRÉS PICO ZÚÑIGA**
}

\begin{abstract}
SUMARIO
Introducción - I. EL DEBER DE INFORMACIÓN EN LA RESPONSABILIDAD POR PRODUCTOS DEFECTUOSOS - A. La buena fe objetiva y los deberes secundarios de conducta - B. El deber de informar en el Estatuto del Consumidor colombiano - C. El deber de evitar y mitigar los daños - II. LA RESPONSABILIDAD ADMINISTRATIVA DEL ARTÍCULO 19 DEL ESTATUTO DEL CONSUMIDOR - A. La ubicación de la regla - B. Las características de la responsabilidad administrativa del artículo 19 - C. Los recall y las medidas correctivas del artículo 19 del Estatuto del Consumidor - III. BREVES CONSIDERACIONES ACERCA DE LA REGLAMENTACIÓN DEL ARTÍCULO 19 DEL ESTATUTO DEL CONSUMIDOR - IV. CONCLUSIONES - Referencias.
\end{abstract}

* Cómo citar este artículo: Pico Zúñiga, F. A. (Junio, 2016). El deber de información en la responsabilidad por productos defectuosos. El artículo 19 del Estatuto del Consumidor colombiano. Revista de Derecho, Comunicaciones y Nuevas Tecnologías, (15). Universidad de los Andes (Colombia). http://dx.doi.org/10.15425/redecom.15.2016.05

** Abogado y profesor de la Pontificia Universidad Javeriana. Magíster en Derecho de la Empresa y de los Negocios de la Universidad de Barcelona. Miembro del Grupo de Investigación en Derecho Privado y el Centro de Estudios de Derecho Privado (CEDP) de la Pontificia Universidad Javeriana. Asesor jurídico de la Presidencia de la Federación Nacional de Comerciantes (FENALCO). Correo: fernandopicozuniga@gmail.com

1. Artículo producto de investigación del Grupo de Investigación en Derecho Privado de la Facultad de Ciencias Jurídicas de la Pontificia Universidad Javeriana, del cual el autor es miembro.

El análisis propuesto mediante el presente artículo se presentó y realizó previa la expedición del Decreto 679 de 2016 , regulador del artículo 19 del Estatuto del Consumidor. 
Introducción

La Ley 1480 de 2011 -Estatuto del Consumidor (EC) - ha constituido, sin lugar a dudas, un cardinal avance social, legislativo y económico en el ámbito jurídico colombiano.

Aunque ya existía en el ordenamiento nacional el Decreto 3466 de 1982, antiguo Estatuto del Consumidor e importante antecedente en materia de protección al usuario, es claro que dicha regulación no constituyó un cuerpo normativo sistemático y uniforme dirigido a garantizar los derechos de los consumidores colombianos, particularmente al amparo de la denominada relación de consumo y la responsabilidad por productos defectuosos, como sí lo ha hecho la todavía novedosa Ley 1480.

Precisamente, por la falta de una normativa nacional que reconociera y respondiera, hasta entonces y con amplitud, a la evolución y apertura comercial, a la masificación de los productos y los contratos, y en general al fenómeno de la sociedad de consumo, que estuviera acorde con los avances y regulaciones sobre la materia en el ámbito jurídico extranjero e internacional, se hizo necesaria la promulgación del hoy vigente EC, a efectos de establecer claros derechos de garantía, publicidad, información, contratación y responsabilidad, a favor del usuario colombiano.

Así, el actual Estatuto es pieza clave no solo en la protección de los derechos de los consumidores, sino además en el entendimiento de las relaciones comerciales y sus implicaciones jurídicas, con trascendentales repercusiones sociales y económicas. Tanto que su expedición ha generado un cambio en el entendimiento de las vinculaciones contractuales y la propia responsabilidad civil tradicional.

Se destaca así, en el nuevo EC, el régimen legal de la responsabilidad por productos defectuosos, que encontró sus cimientos en nuestro ámbito a partir de una serie de pronunciamientos de la Sala de Casación Civil de la Corte Suprema de Justicia y de la Corte Constitucional.

Las normas de la responsabilidad por productos defectuosos, contenidas entre los artículos 19 y 22 del Estatuto del Consumidor -título IV, capítulo único, de la responsabilidad por productos defectuosos-, establecieron un régimen de responsabilidad objetiva en el que, como es bien sabido, no se analiza ni es relevante la conducta del presunto responsable, en este caso la del proveedor o productor, sino un título de imputación, que para estos efectos corresponde a la existencia de un producto defectuoso. En esa medida, habrá débito indemnizatorio a favor del perjudicado cuando concurre un daño que ha sido consecuencia del bien titulado de defectuoso.

Bajo ese entendimiento dispone, primero, el art. 20 del Estatuto: "El productor y el expendedor serán solidariamente responsables de los daños causados por los defectos de sus productos, sin perjuicio de las acciones de re- 
petición a que haya lugar"; y segundo, el art. 21 del mismo cuerpo normativo:

Para determinar la responsabilidad, el afectado deberá demostrar el defecto del bien, la existencia del daño y el nexo causal entre este y aquel.

Parágrafo. Cuando se viole una medida sanitaria o fitosanitaria, o un reglamento técnico, se presumirá el defecto del bien.

Adicionalmente, el art. 22 del Estatuto establece las causales de exoneración alegables por el responsable o presunto responsable del daño cometido por el producto defectuoso, además, eso sí, del decaimiento de los elementos propios de la responsabilidad -la no existencia de defecto, daño o nexo de causalidad entre el primero y el segundo-, que tienen la misma consecuencia exonerativa.

De este modo, podría decirse que el régimen de la responsabilidad por productos defectuosos colombiano se concentra entre los arts. 20 y 22 del EC. Sin embargo, dentro del mismo título IV señalado, el legislador colombiano introdujo en el acápite de la responsabilidad por productos defectuosos el deber de información, que implanta una responsabilidad de tipo administrativo a la que es susceptible cualquier miembro de la cadena de producción, distribución y comercialización que no informe, en los términos del art. 19, sobre la existencia de un defecto en los productos que manipula. Sin perjuicio, eso sí, de la responsabilidad privada que por productos defectuosos pueda generarse.
Así lo determina el tenor literal del artículo 19:

Deber de información. Cuando un miembro de la cadena de producción, distribución y comercialización, tenga conocimiento de que al menos un producto fabricado, importado o comercializado por él, tiene un defecto que ha producido o puede producir un evento adverso que atente contra la salud, la vida o la seguridad de las personas, deberá tomar las medidas correctivas frente a los productos no despachados y los puestos en circulación, y deberá informar el hecho dentro de los tres (3) días calendario siguientes a la autoridad que determine el Gobierno Nacional.

Parágrafo. Sin perjuicio de las responsabilidades administrativas individuales que se establezcan sobre el particular, en caso que el obligado no cumpla con lo previsto en este artículo, será responsable solidariamente con el productor por los daños que se deriven del incumplimiento de esa obligación.

De entrada, la norma referenciada genera inquietudes y discusiones. Establece, en un acápite propio de la responsabilidad privada de productos defectuosos, una responsabilidad de orden administrativo que, en principio y en estricto sentido, nada tendría que ver con la primera.

Por otra parte, el artículo es confuso. Primero, porque no esclarece con notada suficiencia, qué entender por miembro de la cadena de producción, distribución y comercialización. Segundo, porque plantea el interrogante de cómo, desde el punto de vista jurídico y pro- 
batorio, ese miembro de la cadena de producción, distribución y comercialización puede conocer que tiene un producto defectuoso que puede llegar a producir un evento dañoso. Tercero, porque no aclara qué entender por medidas correctivas y, más aún, qué implicaciones tendrían esas medidas en el ámbito de la responsabilidad privada por productos defectuosos, materia de regulación del capítulo del que hace parte la normativa. Y cuarto, porque no advierte qué debe informar el miembro de la cadena a la autoridad: que tiene conocimiento de un producto defectuoso que ha producido o puede producir un hecho adverso, o adicionalmente que ha tomado medidas correctivas para evitar o mitigar los perjuicios.

Por ese motivo y dados los citados cuestionamientos, el presente estudio investigativo se propone comprender el art. 19 del EC colombiano al amparo de las fuentes jurídicas, legales, jurisprudenciales y doctrinales de la protección al consumidor y la responsabilidad civil. En ese sentido, el objetivo se centra en analizar la norma citada y, con ello, plantear unas ideas para su regulación y reglamentación.

De acuerdo con esa finalidad, el presente examen se dividirá en tres grandes partes. Primero, se estudiará el deber de informar en la responsabilidad por productos defectuosos. Así, se analizará el principio de la buena fe objetiva como patrón de conducta en el campo de la responsabilidad civil en general y la responsabilidad por productos defectuosos en particular. Adicionalmente, dentro de ese mismo acápite, se abordará el deber de mitigar los daños como expresión de conducta relacionada con la información y lo que el art. 19 denomina "medidas correctivas". Segundo, se examinará, in concreto, el contenido del art. 19 del EC y se observarán los presupuestos que conforman la responsabilidad administrativa introducida en el citado precepto normativo. Tercero, con fundamento en los puntos primero y segundo, se plantearán una serie de ideas y guías sobre las cuales se podrá instituir y desarrollar una reglamentación del artículo. Por último, se ofrecerán algunas conclusiones.

\section{EL DEBER DE INFORMACIÓN EN LA RESPONSABILIDAD POR PRODUCTOS DEFECTUOSOS}

El deber de información no es una figura novedosa en el campo del derecho y particularmente en el del consumo y de la responsabilidad civil. En efecto, hablar del deber de informar es hacer referencia, de una parte, a las reglas que mandan la información en el ámbito de las relaciones de consumo -art. 23 y siguientes del EC-, y de otra parte, y desde un sentido mucho más primigenio, al ampliamente estudiado principio de la buena fe objetiva, los deberes secundarios o colaterales de conducta, y sus implicaciones en el campo del derecho contractual y el de la responsabilidad.

Así, el deber de informar se establece en el ordenamiento jurídico como una manifestación de la buena fe objetiva, en la medida en que determina un estándar de conducta para las personas, en el orden interno y externo, a la 
hora de desplegar acciones u omisiones en el desarrollo de su vida y sus negocios.

En ese sentido, ha explicado la Sala de Casación Civil de la Corte Suprema de Justicia, al analizar las expresiones e implicaciones de la buena fe en el campo contractual y de la responsabilidad:

La buena fe (...) se torna bifronte, en atención a que se desdobla, (...) en la apellidada "buena fe subjetiva" (creencia o confianza), al igual que en la "objetiva" (probidad, corrección o lealtad), sin que por ello se lesione su concepción unitaria que, con un carácter más panorámico, luce unívoca de cara al ordenamiento jurídico. Al fin y al cabo, (...) es un principio general -e informador- del derecho, amén que un estándar o patrón jurídicos, sobre todo en el campo de la hermenéutica negocial y de la responsabilidad civil.

(Exp. 6146, 2001, C. Jaramillo).

De este modo, en el ordenamiento jurídico el principio de la buena fe ostenta dos grandes dimisiones - subjetiva y objetiva- (De los Mozos, 1965), a partir de las cuales se determinan diferentes funciones dentro de este: informador, integrador, interpretador, normativo, etc. (Ordoqui, 2012, p. 209 y ss.).

Interesa analizar, para los efectos del estudio propuesto, la dimensión objetiva del principio de la buena fe en el campo contractual y de la responsabilidad civil, su función normativa y, en concreto, los deberes de información y de mitigación del daño, como deberes secunda- rios de conducta emanados de la susodicha función. Con ello, y a partir de la manifestación informadora y de mitigación del daño, se logrará comprender de mejor manera y a modo introductorio la inclusión y finalidad de las reglas que mandan el derecho de información de los consumidores -art. 23 y siguientes- y, muy especialmente, el deber de información -art. 19- de que trata el título de la responsabilidad por productos defectuosos del EC.

\section{A. La buena fe objetiva y los deberes secundarios de conducta}

Como se ha indicado, la doctrina y la jurisprudencia distinguen, primordialmente, entre buena fe objetiva y buena fe subjetiva para referirse a las implicaciones externas e internas que el principio tiene en la conducta de la persona.

Al respecto, y aunque el máximo tribunal de la justicia ordinaria colombiana aporta una tercera dimensión del principio, explica la Sala de Casación Civil de la Corte Suprema de Justicia:

La noción de buena fe suele ser contemplada desde tres perspectivas distintas: en primer lugar, aquella que mira el interior de la persona y, por ende, toma en cuenta la convicción con la que esta actúa en determinadas situaciones; en segundo lugar, como una regla de conducta, es decir como la exigencia de comportarse en el trafico jurídico con rectitud y lealtad; y, finalmente, como un criterio de interpretación de los contratos. (Exps. 19979124 02, 2005 y 254.01, 2007, P. Munar). 
De esta manera, cuando se habla de buena fe subjetiva, se hace alusión a un mecanismo o juicio psicológico del sujeto al momento de guiar su conducta, que lo hace pensar que su actuar es correcto. En palabras de De los Mozos (1965), “una guía para la intención” o, según Betti (1969), una actitud de la conciencia que es objeto de una interpretación psicológica; actitud que consiste en la ignorancia de perjudicar un interés ajeno tutelado por el derecho y tiene como consecuencia un efecto justificativo.

Por su parte, la tildada buena fe objetiva, materia de interés, se establece como un parámetro de conducta social debida, una regla de conducta a la que ha de adecuarse el comportamiento jurídico de las personas. De ahí que De los Mozos (1965) sostenga que uno de los aspectos más intensos de la aplicación del principio de la buena fe se encuentre en sus proyecciones mediante la apelada buena fe objetiva, en la medida en que tiene un especial desenvolvimiento tanto en el campo del derecho de las obligaciones como en el de la teoría general del negocio jurídico.

En ese sentido, la Corte Constitucional colombiana ha expresado que el principio de la buena fe "exige a los particulares y a las autoridades públicas ajustar sus comportamientos a una conducta honesta, leal y conforme con las actuaciones que podrían esperarse de una "persona correcta (virbonus)" (C-1194, 2008, R. Escobar). Al amparo del art. 83 de la Carta Política de nuestro país, la consagración constitucional y positiva del principio de la buena fe "significa su incorporación en todas las leyes y en todos los contratos, tanto de derecho público como de derecho privado" (Mansfield, 2003, p. 158 y ss.), arropando cada una de las actuaciones de las personas, de imperioso cumplimiento en la celebración, ejecución e interpretación de sus actos y negocios jurídicos. Lo que implica y se proyecta en las relaciones de consumo.

Así, en ese universo del derecho, del negocio jurídico y la relación de consumo, el principio de la buena fe demanda que los contratantes - productores, proveedores y usuarios- se comporten y desempeñen durante todo el iter contractual, y aún fuera de él, de manera honesta, proba, honorable, transparente, diligente, responsable y "sin dobleces", como ha indicado nuestra Corte Suprema de Justicia (Civil, exp. 6146, 2001, C. Jaramillo), desprovistos del interés de romper el equilibrio prestacional.

Por esa razón, el Código de Comercio y el Código Civil nacionales, que ilustran, permean y se extienden a las reglas que mandan las relaciones jurídicas de consumo y la responsabilidad por productos defectuosos -art. 4 de la Ley 1480 de $2011-^{2}$ indican, primero, el art. 871

2. "En lo no regulado por esta ley, en tanto no contravengan los principios de la misma, de ser asuntos de carácter sustancial se le aplicarán las reglas contenidas en el Código de Comercio y en lo no previsto en este, las del Código Civil. En materia procesal, en lo no previsto en esta ley para las actuaciones administrativas se le aplicarán las reglas contenidas en el Código Contencioso Administrativo y para las actuaciones jurisdiccionales se le aplicarán las reglas contenidas en el Código de Procedimiento Civil, en particular las del proceso verbal sumario." 
del Código de Comercio colombiano, la dimensión del principio de la buena fe en el campo contractual, al señalar que

los contratos deberán celebrarse y ejecutarse de buena fe y, en consecuencia, obligarán no solo a lo pactado expresamente en ellos, sino a todo lo que corresponda a la naturaleza de los mismos, según la ley, la costumbre o la equidad natural,

normativa que no solo se ha utilizado in concreto en los contratos comerciales, sino que ha servido de premisa para encontrarle sentido y alcance al principio de la buena fe en el campo de las relaciones obligacionales (CSJ Civil, exp. 5372, 2000, J. Castillo). Y, segundo, el art. 1603 del Código Civil nacional determina que los contratos "obligan no solo a lo que en ellos se expresa, sino a todas las cosas que emanan precisamente de la naturaleza de la obligación o que por ley pertenecen a ella"; es decir, para que un contrato sea ejecutado de buena fe es indispensable cumplir con todas las obligaciones que se derivan de este, incluyendo aquellas que las partes no pactaron pero que se encuentran en la ley, cuya observancia es presupuesto necesario para la validez y ejecución de toda obligación convencional.

Aún más, cuando el art. 1 del EC regula los derechos de los consumidores sustentado en la dignidad de la persona, y se refiere a principios generales como "el acceso de los consumidores a una información adecuada", "la protección de los consumidores frente a los riesgos para la salud y seguridad", consagra de ma- nera implícita el principio de la buena fe, que desde la normativa superior alumbra todas las actuaciones de las personas (Ordoqui, 2012, p. 209 y ss.).

Así, la buena fe objetiva se manifiesta a través de deberes, obligaciones en el caso concreto, como dice Díez-Picazo (1977, p. 19): “causa o fuente de creación de especiales deberes de conducta exigibles en cada caso", que demandan de los contratantes, en el campo de los negocios, y de las personas en el desempeño de sus actos, dirigir sus acciones con lealtad y solidaridad, lo que les impone el deber de no limitarse a cumplir simplemente con lo literalmente estipulado, sino a ir más allá de los textos legales acordados o dispuestos, con el sincero propósito y la obligación moral y legal de que, mediante el cumplimiento de todas sus obligaciones, el co-contratante, y ambas partes, logren los legítimos propósitos jurídicos y económicos que persiguen con la celebración del acto jurídico.

Implica, así, que el productor o comercializador dirija sus acciones negociales de producción, distribución y comercialización de manera proba, honesta, leal y solidaria con los consumidores. No solo ello, que también los consumidores o usuarios actúen en ese mismo sentido -bien lo indica el numeral 2.2 del art. 3 del EC-. Porque los actos de los productores, comercializadores y consumidores no se limitan o se agotan con el cumplimiento a rajatabla de los artículos legales o las cláusulas contractuales establecidas, sino que se extienden a todas aquellas cosas que -por la propia naturaleza 
de los negocios y el principio de la buena fehagan posible su efectiva realización.

Es precisamente el anterior, el entendimiento de las varias veces señalada buena fe objetiva, con arreglo a la cual el principio general de la buena fe y los deberes que de ella emanan deben ser entendidos en su función normativa e integradora de los actos jurídicos, es decir, con un alcance de complementación de las reglas que mandan las acciones de sujetos y las manifestaciones de voluntad que se traducen en deberes específicos de la conducta de las partes.

En palabras de nuestra Corte Suprema de Justicia, Sala Civil, en su importante sentencia del 2 de agosto de 2001, la buena fe objetiva

se traduce en una regla - o norma- orientadora del comportamiento (directiva o modelo tipo conductual) que atañe al dictado de precisos deberes de conducta que, por excelencia, se proyectan en la esfera pre-negocial y negocial, en procura de la satisfacción y salvaguarda de intereses ajenos (deberes de información; de claridad o precisión; de guarda material de la cosa; de reserva o secreto, etc.). (Exp. 6146, 2001, C. Jaramillo).

De ahí que la doctrina más consabida indique, al referirse a la buena fe objetiva y los deberes de ella nacidos:

En este caso la buena fe, como comportamiento de fidelidad, se sitúa en el mismo plano que el uso o la ley, es decir, adquiere función de norma dispositiva, de ahí su naturaleza objetiva que no se halla basada en la voluntad de las partes, sino en la adecuación de esa voluntad al principio que inspira y fundamenta el vínculo negocial. (De los Mozos, 1965, pp. 45 y 46). [Cursivas añadidas].

En ese sentido, explica Trigo Represas (2009), el principio de la buena fe objetiva y su expresión a través de los denominados deberes secundarios o colaterales de conducta, reglas en los casos concretos, tienen también una importante extensión y efecto en la máxima de la responsabilidad civil "no hacer daño a nadie" (alterum non laedere), consagrada en nuestro ordenamiento jurídico en el art. 2341 del Código Civil, ya que obrar de mala fe, con dolo, con culpa, resulta manifiestamente incompatible con el principio de la buena fe. De este modo, la trasgresión de los señalados deberes secundarios de conducta puede, habida la comprobación de los demás presupuestos de la responsabilidad, derivar en el débito indemnizatorio.

Así las cosas, se pasan a estudiar aquellos deberes relacionados con el art. 19 de nuestro EC, con el objetivo de comprender el fundamento teórico y legal de su consagración normativa.

\section{B. El deber de informar en el Estatuto del Consumidor colombiano}

El deber de informar o de información tiene diferentes apariciones en nuestro ordenamiento, particularmente en el ámbito de las reglas de 
protección al consumidor. Sin perjuicio de ello, su fuente de nacimiento primordial, más allá de la ley, se encuentra en la manifestación objetiva del principio de buena fe, que lo abriga, incorpora y exterioriza.

En el campo de la protección al consumidor, la información como derecho del usuario, presupuesto correlativo al deber, es y ha sido fundamental. Cabe recordar que la relación de consumo, y en consecuencia las normas que la regulan, parten de una situación peculiar: el desequilibro económico entre productores, proveedores y usuarios 0 , en otras palabras, la situación de debilidad del consumidor. Es justamente allí, donde quien cuenta con el mayor conocimiento del bien o servicio que ofrece productor o comercializador-, debe advertir y notificar a su consumidor, de manera clara, veraz, suficiente, oportuna, verificable, comprensible, precisa e idónea, las características del objeto ofertado (art. 23, EC).

Por ese motivo, el deber de información, establecido en artículos como el 1, 3, 4, 19, 23 a 28,29 a 33 relativos a la publicidad, del EC y sus decretos reglamentarios, no es otra cosa que la manifestación y la consagración implícita del principio de la buena fe en ámbito de la protección al usuario.

Ahora bien, en cuanto a su contenido, sostiene Cubides (2008) que el deber de informar se cumple en dos sentidos, a saber: primero, suministrando cada parte a la otra la información que estime adecuada y suficiente para que pueda quedar enterada de las circunstancias en que será celebrado el negocio; y, segundo, informándose cada parte, a sí misma, de los productos o servicios a adquirir. A manera de ejemplo: la calidad, las instrucciones que suministre el productor o proveedor en relación con su adecuado uso o consumo, conservación e instalación.

En las relaciones de consumo, dada la masificación de los productos y servicios, y su correlativa repercusión en los contratos, en especial el hecho de que los contratantes normalmente no están en la capacidad de estar frente a frente, la manera de informar se centra en los datos del bien, disponibles para el consumidor a la hora de aceptar la oferta, así como de la publicidad brindada por los medios de comunicación sobre las virtudes del producto o servicio, la cual tiene como función primordial inducir al consumo. Lo que un sector de la doctrina jurídica denomina, sobre la primera, información de datos u objetiva y, acerca de la segunda, información con opinión (De Ángel Yágüez, 2000).

De ahí que nuestro EC, por vía del capítulo Único del título $V$, De la información, particularmente el art. 24, regule el contenido mínimo y las características generales que deben recibir los usuarios sobre los bienes y servicios que pretenden adquirir o adquieren. $Y$, de otra parte, al amparo del capítulo Único del título VI, De la publicidad, establezca las reglas que mandan las implicaciones de la difusión o anuncio masivo de la información acerca del producto o servicio. Ambos capítulos ordenadores de dos manifestaciones de un mismo deber. 
Así las cosas, la cuestión central radica en determinar si el error en la información; la información inexacta, incompleta o engañosa, ha llevado al otro contratante a una equivocada apreciación de la oferta o el bien. Y, de otra parte, si dichos supuestos pudieron causar los daños sufridos por el consumidor. De ahí que el art. 23 del EC establezca:

Los proveedores y productores deberán suministrar a los consumidores información, clara, veraz, suficiente, oportuna, verificable, comprensible, precisa e idónea sobre los productos que ofrezcan y, sin perjuicio de lo señalado para los productos defectuosos, serán responsables de todo daño que sea consecuencia de la inadecuada o insuficiente información. [Cursivas añadidas].

El deber de información consagrado en el art. 19 del EC no escapa de la enseñada filosofía que guía a las demás disposiciones normativas sobre esa materia y, en especial, el principio de la buena fe. Aunque la implicación del deber de información del art. 19 es de carácter primordialmente administrativo - se observará con mayor detenimiento en el punto 2 de este estudio-, su manifestación en el ámbito de la responsabilidad por productos defectuosos va mucho más allá, se dirige a que los consumidores conozcan, de manera precisa, clara, oportuna, de un defecto de un producto que ha producido o puede llegar a producirles un perjuicio.
En ese sentido vale traer a colación la sentencia del 19 de octubre de 2009, de la Sala de Casación Civil de la Corte Suprema de Justicia (W. Namen) ${ }^{3}$ en la que al tratar el deber de informar en el marco del derecho de los contratos, considera:

Con sujeción al postulado de la buena fe y a ineludibles deberes conexos o coligados al deber central de prestación, en especial, los de protección, transparencia e información, el vendedor está obligado a informar con claridad, precisión y a plenitud al comprador los vicios o defectos que conozca o deba conocer y, por ello, la reparación de los daños encuentra también venero en su inobservancia, por cuanto de conocerlos o haber logrado conocerlos, podía evaluarlos y abstenerse de contratar o hacerlo en términos diferentes. Tales deberes son más intensos en quienes se dedican habitual o profesionalmente a la venta, ya de manera exclusiva, concurrente o conexa con otras actividades, (...) sea por sí mismo o por otro, en cuyo caso, han de adoptar todas las medidas exigibles, razonables e idóneas para conocer e informar el exacto estado de la cosa. [Cursivas añadidas].

Por ese motivo, el deber de información de que trata el citado art. 19 no se agota con la simple notificación del defecto a la entidad administrativa designada para ese fin. Se encamina a que el miembro de la cadena de producción,

3. Ver también: Corte Suprema de Justicia. Sala de Casación Civil. Ref.: 11001-3103-040-2006-00537-01 (21 de febrero de 2012). 
distribución y comercialización lo informe y lo dé a conocer al mercado. No de otra manera, a la luz de la buena fe objetiva y lo que el art. 19 establece como medidas correctivas, puede leerse dicha disposición normativa. Más todavía, porque el propio parágrafo de la regla dispone:

Sin perjuicio de las responsabilidades administrativas individuales que se establezcan sobre el particular, en caso que el obligado no cumpla con lo previsto en este artículo, será responsable solidariamente con el productor por los daños que se deriven del incumplimiento de esa obligación.

\section{El deber de evitar y mitigar los daños}

Como sostiene con notada lucidez el profesor Carlos Ignacio Jaramillo (2013, p. 12), asistimos al reverdecimiento y la renovación de axiomas como el de la buena fe y un mejor empleo del abuso del derecho. En efecto, las normas de protección al consumidor son una de las múltiples muestras del florecimiento que, en la actualidad, ostentan las anotadas figuras jurídicas.

Así, el derecho moderno busca, además de una cultura de solidaridad y equilibrio de fuerzas entre las partes contratantes ante la realidad socioeconómica vigente, una sostenida cultura preventiva, en la que las personas, en la medida de sus conocimientos y posibilidades, se anticipen a las eventuales consecuencias dañosas de sus actos o, en caso de establecerse el menoscabo, aminorar los efectos negativos de este.

Por ese motivo, Matilde Zavala (2004) sostiene que "el daño menoscaba la vida, mientras que prevención y reparación la favorecen" (p. 25). Más aún, afirma que

el Derecho de daños no versa únicamente sobre los perjuicios y sus consecuencias jurídicas, sino que se ha expandido como un Derecho sobre los derechos que no deben ser dañados (...) es un derecho a la preservación y no únicamente un Derecho de la reparación. (P. 26).

De ahí que la misma autora concluya que se puede hablar de un derecho a no ser víctima, correlativo al alterum non laedere.

De este modo, los deberes de evitar y mitigar el daño tienen una fuente de nacimiento bifronte: el principio de la buena fe, particularmente su expresión objetiva, y el propio alterum non laedere de la responsabilidad civil, a partir de su función preventiva y el consabido principio de la reparación integral del daño. ${ }^{4}$

4. Al respecto considera nuestra Corte Constitucional: “Dentro de la sistemática del daño establecida en el orden jurídico colombiano, el principio de reparación integral no excluye la posibilidad de que el legislador a quien corresponde efectuar el diseño normativo de la responsabilidad derivada del incumplimiento contractual, contemple algunas limitaciones que sean compatibles con el principio de equidad que debe regir esta materia. En efecto, no es contrario al orden justo que promueve la Constitución la regla que establece que todo deudor incumplido, actúe con dolo o con culpa, está obligado a responder de todos los daños que sean consecuencia inmediata y directa del incumplimiento, y que paralelamente limite los daños impu- 
Se trata, en consecuencia, de dos deberes íntimamente atados entre sí. No solo ello, están unidos también a deberes colaterales como el de información y cooperación, que provienen de una misma fuente productiva: el varias veces citado principio de la buena fe. Por ello, con razón certera indica Mariana Bernal Fandiño (2012, p. 45): “Dentro del deber de cooperación (...) se encuentran incorporados otros deberes como el de información y la obligación de seguridad. En nuestra opinión, se encontraría cobijada también la exigencia de mitigar el daño."

Ahora bien, sin perjuicio de su relación, evitar y mitigar el daño son deberes con contenidos disímiles. El deber de evitar, como se desprende de su definición, se funda en el propósito de procurar que el daño no se produzca, por lo que se ubica en una etapa anterior a su manifestación o materialización. Se trata, así, de una manifestación preventiva del moderno derecho de daños, interesado en que hasta lo racional y objetivamente posible no se conciba el perjuicio.

Por su parte, el deber de mitigar, atenuar, disminuir o contraer el daño, entre otras tantas designaciones, se sitúa en un momento diferente: después (ex post) de la consecución del menoscabo, lo que un sector doctrinal denomina "posdaño". En ese sentido, el objetivo del deber radica en procurar que los efectos del perjuicio no se propaguen o se extiendan, por lo que lo deseable es frenar su desenvolvimiento o ampliación, una vez acaecido.

Así, en ambas figuras la víctima potencial, acreedora de la condicionada obligación indemnizatoria, debe actuar de manera y en momentos diferenciales, aunque bajo una misma materia: en un primer caso inhibir la generación del menoscabo; en el segundo, amortiguar los efectos del perjuicio.

En esa línea,

en una secuencia lógica, primero emergerá el deber de evitar, acorde con la fase de prevención, y si no es viable conjurar la malhadada aparición del (...) perjuicio, debe tener cabida el de mitigar ante la realidad insoslayable y cruda de su surgimiento. (Jaramillo Jaramillo, 2013, p. 159).

De ahí que Rodrigo Fuentes Guiñez (2006, p. 26) sostenga, en lo que tiene que ver con la diferenciación y caracterización de los citados deberes:
En doctrina se ha señalado que comprende dos deberes: por un lado, un deber de evitar la verificación de un daño que aún no se ha

tables al contratante no doloso, a aquellos que podían preverse al momento de contratar." (CConst., C-1008/10, L. Vargas). Anota Luis Díez-Picazo (2011), al analizar el nacimiento del deber de mitigación: "Esta regla encuentra su fundamento en el principio general de buena fe, tal y como se encuentra consagrado en el art. 7 C.C. Es evidentemente contrario a la buena fe aprovechar un accidente culposo para agravar la situación del causante del daño." (P. 344).

Ver también: Solarte Rodríguez (2004, pp. 303 y ss.), Benítez Caorsi (2006), Domínguez Hidalgo (2012, pp. 134 y 135) y Jaramillo Jaramillo (2013, pp. 159 y ss.). 
producido. Por otro lado, comprende el deber de mitigar un daño que se ha producido.

Aunque la doctrina ha analizado con mayor suficiencia el deber de evitar y mitigar el daño como deber en cabeza del presunto acreedor -víctima-, debe tenerse presente que los citados deberes son predicables también del probable causante del perjuicio. Y no podría ser de otra manera, si al amparo del principio del alterum non laedere y la buena fe se le exige a la víctima actuar con solidaridad, en cooperación con su victimario, en aras de evitar y mitigar el daño que se le ha causado, hasta lo razonablemente posible, también el presunto culpable debe obrar de buena fe y, en línea con la solidaridad conductual, prevenir y minimizar los perjuicios que su actuar hayan podido generar (Cubides, 2008, p. 258). ${ }^{5}$

En efecto, ya de antaño enseñaban Planiol y Ripert (1940) y Messineo (1979, pp. 479 y 480), a partir del análisis de las instituciones clásicas de la responsabilidad civil, que todo daño originado en una abstención es fuente de responsabilidad y que, para el surgimiento de la obligación de reparar, debe observarse si el causante pudo representarse la posibilidad del daño y el poder de evitarlo. Más aún, explica el jurista alemán Karl Larenz (1958, p. 591), cuando se da o existe un deber jurídico a evitar su causación. El daño producido ha de imputarse objetivamente al obligado, como consecuencia de su inactividad, siempre que hubiese podido evitarse si él hubiese actuado conforme a su deber. (...) sí existe un deber de evitar un riesgo allí donde alguien está obligado por ley (p. ej.: al cuidado de ciertas personas) o por medio de contrato a la protección y vigilancia de otro (como $p$. ej.: el profesor de natación, el enfermero, la directora de un colegio de párvulos). Además de esto, la jurisprudencia ha desarrollado el principio de que aquel que crea o mantiene en el tráfico una fuente de peligros, especialmente el que soporta produce en su inmueble o en sus locales un tráfico público o expone cosas al tráfico general, está obligado a adoptar las precauciones que sean necesarias para evitar peligros a los participantes en el mismo tráfico (deber de seguridad del tráfico).

En nuestro entorno, la citada posición doctrinal, compartida por tratadistas como Luis de Gásperi (1945, p. 718) y Karl Larenz (1958, p. 591), ha sido acogida también por nuestra Sala de Casación Civil de la Corte Suprema de Justicia mediante la sentencia del 12 de mayo de 1952, reiterada en sentencia hito del 30 de septiembre de 2002, al indicar:

5. Indica Cubides Camacho, al analizar las implicaciones de la buena fe en las partes involucradas mediante contrato o la obligación indemnizatoria, que a partir del principio de la buena fe emana "el deber de buscar la indemnidad, es decir buscar cada agente del acto que no se produzca daño al otro, bien evitándolo o bien resarciendo los perjuicios causados. Dentro de este deber de indemnidad quedarían obligaciones como las siguientes: (...) 2. Mitigar los daños propios cuando se es perjudicado y la otra parte debe indemnizar, para lo cual debe actuar con diligencia y acuciosidad a fin de reducir, tanto como sea posible, el perjuicio que ha sufrido, y en todo caso de evitar cualquier actuación o descuido que conlleve daños adicionales." (2008, p. 258). 
Esta Corporación, en sentencia del 12 de abril de 1946, prohijando la tesis que predica la existencia de un deber - de conformidad con una concepción lata- para el potencial responsable, corroboró que "No solamente la comisión de hechos positivos hace incurir en culpa, sino que el simple descuido, la negligencia la producen, de acuerdo con el Código Civil. En el derecho moderno, como enseña Josserand, se abre a un campo cada día más amplio a la doctrina de que no solo por hechos activos - como cuando derribamos a un peatón o difamamos al prójimo- $\underline{\text { se }}$ compromete nuestra responsabilidad, sino también por abstención, por la inercia. A la falta positiva viene a oponerse y agregarse la falta negativa, que consiste en abstenerse de un acto, de una intervención, de una iniciativa que se estiman obligatorios. Podemos pecar por abstención, tanto como por acción; por inactividad, como por agitación. [Subrayas en el original].

De ahí que, precisamente y con mayor veras al amparo de la responsabilidad objetiva por productos defectuosos, el art. 19 del EC sancione la omisión de acción del miembro de la cadena de producción, distribución y comercialización que, teniendo conocimiento de la existencia de un producto defectuoso fabricado, importado o comercializado por él, que ha producido o puede producir un evento adverso que atente contra la salud, la vida o la seguridad de las personas, no informe el hecho a la autoridad competente y tome las medidas correctivas frente a los bienes despachados. En otras palabras, el productor, distribuidor o comerciali- zador que omita informar, evitar o mitigar los daños que sus productos defectuosos puedan causar al público, puede ser sujeto de sanciones administrativas, además de las implicaciones que, en el ámbito de la responsabilidad por productos defectuosos, su inacción pueda generar.

Vale advertir que los deberes de evitar y mitigar el daño no se encuentran expresa y manifiestamente establecidos en el art. 19 del EC. Sin embargo, cuando el citado art. 19 alude a que el miembro de la cadena de producción, distribución y comercialización debe "tomar las medidas correctivas frente a los productos no despachados y puestos en circulación" que tienen un defecto que ha producido o puede producir un evento adverso contra los bienes jurídicos de las personas, se refiere específicamente al acatamiento de los analizados deberes de evitar y mitigar el perjuicio.

Es importante señalar y reiterar, en todo caso, que la consagración normativa de los citados deberes acentúa su acatamiento y las implicaciones administrativas que genera su incumplimiento, ya que, sin necesidad de disposición legal expresa, por vía del principio de la buena fe y el alterum non laedere, los varias veces citados deberes son siempre exigibles entre las personas.

De este modo, una lectura completa del art. 19 permite dilucidar que tomar las medidas correctivas implica impedir el nacimiento de daños que puedan llegar a causar los productos defectuosos o atenuar los perjuicios produ- 
cidos por los mismos bienes. Por ese motivo, las denominadas medidas correctivas del art. 19 no son otra cosa que medidas de evasión y mitigación de los daños, dirigidas a frenar y atenuar las consecuencias lesivas de los productos defectuosos.

Aunque en particular, de acuerdo con el tenor literal del art. 19, los miembros de la cadena de producción, distribución y comercialización deben tomar las medidas correctivas frente a los productos, se considera que, a efectos de evitar y mitigar los daños, los actores de las cadenas no se deben circunscribir a aquellas acciones relacionadas únicamente con sus bienes. Como lo ha dilucidado con notada suficiencia tanto la jurisprudencia como la doctrina, no existe un catálogo absoluto y exhaustivo de qué entender por medidas razonables. Ello, en definitiva, deberá esclarecerse en cada caso concreto.

Al respecto se destaca la Sentencia del 16 de diciembre de 2010, de la Sala de Casación Civil de la Corte Suprema de Justicia que, al estudiar la cuestión en el campo del contrato de transporte, consideró:

No puede extenderse, ni ello compete a la Corte, una lista acabada o exhaustiva de las medidas que un transportador debe implementar, según las exigencias de su profesión, frente a situaciones concretas, con el fin de evitar el perjuicio o su agravación, pues, en línea de principio, es él quien, en su momento y lugar, debe identificar los riesgos asociados a su negocio, medir el nivel de exposición respecto de ellos, al igual que la posibilidad de conjurarlos y emprender las acciones que estime prudentes y adecuadas, las cuales, en caso de controversia, estarán sometidas, por obvias razones, a la ponderación del juzgador, conforme los dictados del sentido común y la sana crítica (Cas. Civ., sentencia de 8 de noviembre de 2005, arriba citada).

Lo que reafirma, por una parte, que en esta materia cada caso particular determinará la razonabilidad de las medidas adoptadas por el transportador y, por otra, la imposibilidad de calificar a priori que ciertas medidas sean razonables y que otras no cumplan con dicho calificativo (CSJ Civil, 2010, W. Namen).

Con todo, hasta aquí, puede apreciarse cómo el art. 19 del EC encuentra un fuerte sustento jurídico en los principios básicos del derecho y la responsabilidad civil, que se manifiestan de manera concreta en los analizados deberes de informar, evitar y mitigar el daño. Con fundamento en ello, aunado al entendimiento que al respecto ha tenido la Superintendencia de Industria y Comercio, se analizará la responsabilidad administrativa introducida por la disposición bajo examen.

\section{LA RESPONSABILIDAD} ADMINISTRATIVA DEL ARTÍCULO 19 DEL ESTATUTO DEL CONSUMIDOR

Bajo el presente título se estudiarán las características generales de la responsabilidad introducida en el art. 19 del EC. Para ese efec- 
to, se analizará la ubicación de la regla en el mundo de las normas de protección al usuario colombiano, en particular en el EC, para luego, con fundamento en las consideraciones del título 2 del presente documento, abordar las particularidades e implicaciones jurídicas del precepto normativo tanto en su dimensión administrativa como en el de la responsabilidad por productos defectuosos.

\section{A. La ubicación de la regla}

Como ya se ha venido indicando, el art. 19 del EC introduce un régimen de responsabilidad administrativa atípica y exótica dentro de los acápites de la responsabilidad por productos defectuosos.

En efecto, desde el derecho comparado, las reglas que mandan deberes de información, evasión y mitigación del daño frente a la autoridad administrativa, derivados del conocimiento que tiene el productor o comercializador sobre la existencia de defectos en sus productos que pueden ocasionar daños a los consumidores, se encuentran establecidas en las normativas relacionadas con la protección a la salud de los usuarios y seguridad de los productos, que no en el régimen de la responsabilidad por productos defectuosos, como se hizo en Colombia.

Así, es dable citar y traer a colación, desde el ámbito jurídico de la Unión Europea, la Directiva 2001/95/CE, de 3 de diciembre de 2001, relativa a la seguridad general de los productos, ${ }^{6}$ que establece, bajo su extenso art. 5, referente a las obligaciones de los productores y distribuidores:

1. Dentro de los límites de sus respectivas actividades, los productores proporcionarán a los consumidores información adecuada que les permita evaluar los riesgos inherentes a un producto durante su período de utilización normal o razonablemente previsible, cuando estos no sean inmediatamente perceptibles sin avisos adecuados, a fin de que puedan precaverse de dichos riesgos. La existencia de tales avisos no eximirá del respeto de las demás obligaciones establecidas en la presente Directiva. Igualmente dentro de los límites de sus respectivas actividades, los productores adoptarán medidas apropiadas, según las características de los productos que suministren, de manera que puedan: a) mantenerse informados de los riesgos que dichos productos puedan presentar; $b$ )

6. Bajo las consideraciones de la Directiva se dispone, sobre la materia objeto de examen, lo siguiente: “19. Entre las obligaciones adicionales de los productores, debe figurar la de adoptar medidas que, proporcionalmente a las características de los productos, les permitan obtener información sobre los riesgos que pueden presentar; suministrar a los consumidores una información que les permita evaluar y prevenir los riesgos; avisarles de los riesgos que presentan los productos peligrosos que ya les hayan sido suministrados; retirarlos del mercado y, como último recurso, recuperar estos productos en caso necesario, lo que puede acarrear, según las disposiciones aplicables en los Estados miembros, una forma adecuada de compensación, por ejemplo, el cambio de los mismos o el reembolso. (...) 36. La presente Directiva no debe tener efectos sobre los derechos de los perjudicados, a efectos de la Directiva 85/374/CEE del Consejo, de 25 de julio de 1985, relativa a la aproximación de las disposiciones legales, reglamentarias y administrativas de los Estados miembros en materia de responsabilidad por los daños causados por productos defectuosos." 
actuar en consecuencia, si fuera necesario, retirando del mercado el producto para evitar dichos riesgos, avisando de manera adecuada y eficaz a los consumidores, o recuperando los productos de los consumidores.

Más aún, el numeral 3 del citado art. 5 de la Directiva 2001/95/CE, que parece ser acogida con similitud por nuestro art. 19 del EC, dispone:

3. En los casos en que los productores y los distribuidores sepan o deban saber, por la información que poseen y como profesionales, que un producto que ya han puesto en el mercado presenta para el consumidor riesgos incompatibles con la obligación general de seguridad, informarán inmediatamente a las autoridades competentes de los Estados miembros en las condiciones fijadas en el anexo I, precisando, en particular, las medidas adoptadas para prevenir los riesgos para los consumidores. La Comisión adaptará, mediante el procedimiento establecido en el apartado 3 del art. 15, los requisitos específicos para esta obligación de información que figura en el anexo I. ${ }^{7}$ [Cursivas añadidas].

Por ese motivo, como es dable apreciar, el primer gran comentario con respecto al art. 19 de nuestro EC se centra en que se encuentra mal ubicado dentro del régimen de protección al consumidor colombiano.

Ello, aunque pareciera ser una simple cuestión formal y de técnica jurídica, va mucho más allá. El asunto se relaciona y toca, con notada profundidad, la filosofía y entendimiento de la norma, como se tuvo la oportunidad de analizar en el título 2 del presente estudio. Es diferente hablar de un deber de informar, evitar y mitigar los daños frente a los consumidores, que de un estricto deber de información, y tomar las medidas correctivas de cara a la autoridad administrativa para impedir o aminorar los perjuicios a los consumidores. Bien lo ejemplifica el citado art. 5 de la Directiva 2001/95/ $\mathrm{CE}$, mencionada con anterioridad, que regula los dos supuestos bajo un mismo artículo pero en numerales diferentes.

Por ello, se reitera y subraya, el art. 19 del EC cobija un interés dual o bifronte. Primero, de manera expresa, frente a la administración, en el entendido que el miembro de la cadena de producción o comercialización debe informar a la autoridad del defecto de su producto que ha generado o puede generar un daño contra la seguridad, la salud o la vida de las personas, y, en ese sentido, tomar las medidas correctivas frente a los productos no despachados y puestos en circulación. Pero, de otra parte, no menos importante y en segundo lugar, frente a las personas y consumidores. Se trata, entonces, de que los agentes de fabricación o distribución informen al público en general del defecto del producto que ha causado o puede llegar a causar un perjuicio; adicionalmente, que los mismos actores económicos, eviten y mitiguen los daños que se puedan llegar a producir o re-

7. En ese mismo sentido vale destacar, en el ámbito jurídico español, el Real Decreto 1801/2003, de 26 de diciembre, sobre seguridad general de los productos. 
duzcan las consecuencias lesivas de aquellos que hayan nacido.

En efecto, la propia Superintendencia de Industria y Comercio colombiana, al examinar el alcance del deber de información de que trata el art. 19, conceptuó:

El citado art. 19 de la Ley 1480 de 2011 no regula expresamente la forma en que se debe informar a los consumidores cuando se presenten los supuestos de hecho de dicha norma, y la Superintendencia de Industria y Comercio a la fecha no ha impartido instrucciones sobre la materia. Sin embargo, se debe tener en cuenta el derecho a la seguridad e indemnidad que tienen los consumidores: (ver art. 3, num. 1.2, del EC) (...) Por lo cual, en dichos casos deberá informar a los consumidores en la forma en que sea idónea para garantizar los derechos de estos. (Concepto 12-171565-4-0, 2012).

De ahí que el art. 19 sub examine tenga, además de implicaciones administrativas, repercusiones en el plano de la responsabilidad por productos defectuosos. Ello no solo se deriva de las consideraciones elevadas en las líneas previas, sino de la misma disposición normativa que, en su parágrafo, señala:

Sin perjuicio de las responsabilidades administrativas individuales que se establezcan sobre el particular, en caso que el obligado no cumpla con lo previsto en este artículo, será responsable solidariamente con el productor por los daños que se deriven del incumplimiento de esta obligación.
Al respecto se mostrarán a continuación las consideraciones que cabrían para abordar la cuestión desde el punto de vista regulatorio.

\section{B. Las características de la responsabilidad administrativa del artículo 19}

A efectos de abordar las particularidades propias del art. 19 del EC se pasa a analizar las siguientes cuestiones:

1. ¿Qué entender por miembro de la cadena de producción, distribución y comercialización? Aunque parezca elemental, las partes de la cadena de que trata la norma estudiada son los productores, distribuidores o comercializadores. De este modo, la respuesta al interrogante está determinada por el propio EC en su art. 5, al definir que es productor "quien de manera habitual, directa o indirectamente, diseñe, produzca, fabrique, ensamble o importe productos. También se reputa productor, quien diseñe, produzca, fabrique, ensamble, o importe productos sujetos a reglamento técnico o medida sanitaria o fitosanitaria"; y es proveedor o expendedor "quien de manera habitual, directa o indirectamente, ofrezca, suministre, distribuya o comercialice productos con o sin ánimo de lucro."

Así las cosas, son productores: el fabricante, dentro del que se encuentra el doctrinariamente denominado fabricante aparente (Richard, 1997, p. 313), el ensamblador, el 
diseñador y el importador; y, de la otra, son distribuidores y comercializadores: los proveedores y expendedores de productos. De manera que es a ellos a quienes les son aplicables las obligaciones de información y de medidas correctivas de que trata el art. 19.

2. ¿Cómo saber que un miembro de la cadena de producción, distribución y comercialización conoció del defecto del producto que ha generado o puede generar un evento adverso? Conocer es un presupuesto fundamental para el ejercicio del deber de información. Solo quien conoce puede informar. Por ese motivo, dos son los supuestos que deben existir a efectos de cumplir con el citado deber de información: primero, conocer del hecho de interés y, segundo, comunicarlo a las personas o autoridad respectiva.

Ahora, en lo que refiere al conocimiento, ha dilucidado la doctrina especializada que conocer es un proceso psicológico e interno, mediante el cual la mente humana capta un objeto. De este modo, el conocimiento es una relación que se entabla entre un sujeto y un objeto, en virtud de la cual el sujeto incorpora o adquiere en su mente la realidad o verdad del objeto conocido.
Este hecho, de orden interno y psicológico, plantea una dificultad trascendental desde el plano jurídico en nuestro caso: ¿cómo saber, a efectos de imputar la correspondiente sanción administrativa, que el miembro de la cadena supo del defecto del producto defectuoso del que debía informar?

Para esa finalidad habrá de sustraerse del plano eminentemente subjetivo y encontrar elementos objetivos relacionados con el miembro de la cadena, a propósito de dilucidar si tuvo conocimiento del defecto del producto.

Así, debe acudirse al consabido criterio del buen hombre de negocios, propio de la responsabilidad civil, para determinar si un fabricante, distribuidor o comercializador diligente (Chinchilla Imbett, 2011), ${ }^{8}$ con las mismas o similares características, situación y condiciones de quien se juzga, debía conocer del hecho. De este modo, el juzgador esclarecerá, conforme a indicios, pruebas, si efectivamente el miembro de la cadena conoció del producto defectuoso y si, en esa línea, incumplió el deber de informar.

En ese sentido, indica Le Tourneau (2006, p. 149) al analizar la obligación de infor-

8. “La exigencia de diligencia como límite al deber de información debe conmensurarse a las cualidades del sujeto al que se dirige tal diligencia, el cual se analizará en el caso en concreto. Así por ejemplo, aún al comprador de un vehículo usado, sin conocimientos técnicos en mecánica, le es exigible un comportamiento diligente adecuado a su condición, diligencia que no consistirá en verificar el estado mecánico del vehículo a la manera de un perito, pero sí le será exigible hacer un examen del estado aparente del vehículo antes de la compra del mismo para que se informe según sus capacidades y sus conocimientos de los vicios que resulten evidentes. Diferente es la diligencia exigida si el comprador es un perito con experticia en el campo automotriz, la cual le exige a dicho comprador un examen más detallado que le permita informarse tanto de los defectos manifiestos como de los que no lo están, toda vez que por razón de su oficio o profesión debe o debía fácilmente reconocerlos" (Chinchilla Imbett, 2011, A. Diligencia de las partes..., párr. 7). Ver también: Meruzzi (2002, p. 162). 
mación de los profesionales en el marco contractual, que dicha obligación envuelve actos adicionales por parte del profesional, dado su carácter experto. De este modo, señala el mismo autor:

Para poder informar con conocimiento de causa a su cocontratante, es a veces necesario que el profesional le solicite precisiones; que se informe de sus necesidades y de sus objetivos: "Todo vendedor de un material debe, con el fin de que la venta sea concluida con conocimiento de causa, informarse de las necesidades de su comprador" (Cas. Com., del $1 .^{\circ}$ de diciembre de 1992), incluso de su situación financiera y de su experticia (en ese sentido C. Mon. Fin., art. L. 341-11, a propósito del corretaje bancario o financiero). De todas maneras, es casi siempre en relación con un tercero, especialmente un proveedor, que estas informaciones deben ser averiguadas. En los casos extremos, incumbe al profesional proceder a estudios previos y a investigaciones.

De este modo, al profesional -el miembro de la cadena de producción, distribución o comercialización- le es exigible una diligencia calificada, en los términos anteriormente indicados, que el juzgador deberá esclarecer junto al arsenal probatorio recopilado en el caso concreto.
Por ese motivo, aunque la obligación de informar de que trata el artículo 19 del EC es una obligación de resultado, no lo es la del conocimiento, que debe determinarse de acuerdo con la diligencia calificada del miembro de la cadena de producción, distribución o comercialización dirigida a ese efecto.

3. ¿Qué significa que un producto defectuoso ha producido o puede producir un evento adverso contra las personas? Sin abordar con amplitud el concepto de producto defectuoso, que se trata de toda una materia de análisis, es dable definir el producto defectuoso como aquel bien o servicio que no responde al atributo de seguridad objetivamente esperado por los consumidores (numeral 17, art. 5 EC). En ese sentido, la ley, ${ }^{9}$ la doctrina y la jurisprudencia han identificado una serie de categorías en las que puede enmarcarse el defecto. Se destaca, dentro de ellas, aquella clasificación que indica que los defectos pueden ser de tres tipos generales, a saber: de fabricación, de diseño o de información. De este modo, el producto es defectuoso si su elaboración, su delineación o la información suministrada por el productor o comercializador hacen que el bien sea objetivamente inseguro para los consumidores.

Sin embargo, cuestión más compleja nos plantea el art. 19 del EC. Indica la dispo-

9. La normativa de protección al consumidor colombiano, al amparo del citado numeral 17 del art. 5 del EC, el cual define el concepto de producto defectuoso, establece que los defectos del producto pueden ser "un error (en) el diseño, fabricación, construcción, embalaje o información." 
sición, que el miembro de la cadena debe informar del producto defectuoso que haya producido o pueda producir un evento adverso que atente contra la salud, la vida o la seguridad de las personas. Así, se plantean otros interrogantes dentro del que ab initio se ha propuesto, ¿qué es un evento adverso y cuándo se causa o puede llegar a causarse?, ¿es acaso, el evento adverso, sinónimo de daño?

Al respecto, debe indicarse que la expresión evento adverso es una locución primigeniamente del escenario médico y en particular de la protección de la salud de los pacientes. ${ }^{10}$ Por ese motivo, la Resolución 4816 de 2008 del entonces Ministerio de la Protección Social, relativa a la reglamentación del Programa Nacional de Tecnovigilancia, definió en su art. 2: “Evento adverso. Daño no intencionado al paciente, operador o medio ambiente que ocurre como consecuencia de la utilización de un dispositivo médico."

Por ese motivo, el evento adverso al que se refiere el citado art. 19 del EC, no es otra cosa que un menoscabo o perjuicio en la salud, la vida o la seguridad de las personas, que ya ha generado el producto o puede llegar a generar, bien porque así se ha acreditado en el escenario local, extranjero o internacional, o porque, dada la característica de inseguridad, identificada o conocida por el miembro de la cadena de producción o co- mercialización in extenso, el producto puede llegar a causar detrimento en los bienes jurídicos del público en general.

4. ¿Qué debe informar el miembro de la cadena de producción: el defecto del producto que ha causado o puede causar consecuencias adversas a las personas, o las medidas correctivas? Como se ha tenido la oportunidad de ver, de la lectura detenida del art. 19 no es dable concluir, con claridad meridiana, que el miembro de la cadena solo tenga que informar a la autoridad del defecto del producto que ha generado o puede generar consecuencias lesivas a las personas, o, por contera, de las medidas correctivas tomadas o que serían asumidas por él. En efecto, como lo ha dilucidado la Superintendencia de Industria y Comercio, este es uno de los asuntos fundamentales que debe aclararse a la luz de la reglamentación que se expida de la norma (Conceptos 12-171565-4-0 y 12-196442-3-0, 2012).

Sin perjuicio de ello, se considera que el miembro de la cadena debe informar sobre el defecto del producto, las consecuencias o eventuales consecuencias adversas que podría generar, así como de las medidas correctivas que ha adoptado o aquellas que serán objeto de adopción, básicamente por dos razones: primera, porque el deber de informar envuelve y se encuentra íntimamente atado a las medidas correctivas para evitar

10. En ese sentido ver: Agencia Española de Medicamentos y Productos Sanitarios (2015) y Unión Europea (2010). 
o minimizar las consecuencias lesivas que se hayan ocasionado o puedan ocasionarse con el producto defectuoso; y, segunda, porque la ubicación y la finalidad definitiva del precepto normativo, como se ha tenido la oportunidad de analizar, advierte que el art. 19 busca, además de dar a conocer al público en general los riesgos de perjuicio de un producto en específico, que dicho producto no genera daños. De manera que no basta y nada se hace con que el miembro de la cadena simple y pasivamente informe del defecto del producto, debe adicionalmente avisar sobre las medidas correctivas que ha tomado o que piensa asumir frente al hecho.

Ahora, no se considera que en el lapso de los tres días ofrecidos por la normativa se informe y adicionalmente se tomen efectivamente las medidas correctivas. Se trata de que en dicho periodo se comunique del defecto, así como de las medidas de corrección tomadas o a asumir por parte del miembro de la cadena. En definitiva, el deber de que trata el precepto bajo examen es de información, aunque incorpore el de acción en cuanto a la corrección frente al producto defectuoso.

5. ¿Cuáles son las medidas correctivas? ¿solo se limitan a los productos? Sobre este punto ya me he pronunciado por vía del análisis de los deberes de evitar y mitigar el daño y su relación con el art. 19 del EC. Así las cosas, aunque al tenor literal del art. 19 es claro que las medidas correctivas recaen sobre los productos, se cree y reitera que, a la luz del principio del alterum non laedere, la buena fe objetiva, los deberes de evitar y mitigar el daño, las medidas de corrección no son un numerus clausus de acciones sobre un bien en concreto, su objetivo es el de corregir la situación dañina ocasionada o que pueda llegar a ocasionarse, lo que extiende su aplicación a todos los campos necesarios, relacionados con el supuesto fáctico, para que el producto no genere o se reduzcan sus efectos perjudiciales. (Ver el numeral I, literal $C$ del presente estudio).

\section{Los recall y las medidas correctivas del artículo 19 del Estatuto del Consumidor}

En el marco del interrogante planteado cabe también referirse brevemente a los recall, expresión que se ha usado para referirse al deber de información consagrado en el art. 19 del EC. Al respecto vale subrayar que la figura de los product recall o simplemente recall y el deber de informar del art. 19 del EC son instituciones jurídicas diferentes, aunque íntimamente relacionadas.

En efecto, los product recall, también conocidos por su traducción al español como "la retirada o recogida de productos" o "campaña de seguridad", propias del ámbito jurídico anglosajón, es una figura jurídica bajo la cual un empresario, fabricante o comercializador, solicita a sus consumidores devolver un producto después de que se han descubierto, en él, pro- 
blemas de seguridad o defectos que puedan poner en peligro a los usuarios, o al propio productor o comercializador frente a eventuales acciones legales.

Así las cosas, el recall puede consistir en que el fabricante o productor retire del mercado la serie o lote de productos objeto del defecto; también, en impartir instrucciones hacia sus consumidores con respecto al buen uso del bien, así como las medidas que los usuarios deberán tomar frente al producto que tienen en su poder.

Justamente, por la similitud de la figura anglosajona del recall con el deber de información del EC colombiano, algunos profesionales del derecho han usado, indistintamente, el apelativo recall para referirse al art. 19 del EC. Sin embargo, y aunque se estima que existen elementos afines y vinculantes entre las dos instituciones -el deber de información y la señalada figura del recall-, se tratan de dos instituciones diferentes en la medida en que nuestro art. 19 permite un campo de acción mucho más amplio, tanto como para generar medidas correctivas que sobrepasan el llamamiento o la recogida del producto. Adicionalmente, porque el asunto central del art. 19 no es la recogida de productos defectuosos, sino la información a la autoridad administrativa de la existencia del hecho, así como de las medidas correctivas para paliar la situación.

\section{BREVES CONSIDERACIONES ACERCA DE LA REGLAMENTACIÓN DEL ARTÍCULO 19 DEL ESTATUTO DEL CONSUMIDOR}

Habidas todas las consideraciones previas referentes al art. 19 del EC, se pasa a enlistar las siguientes ideas que, a mi entender, deberán ser tenidas en cuenta al momento de regular la disposición normativa bajo examen. ${ }^{11}$ Veamos:

1. La reglamentación debe determinar cuándo se entiende que un miembro de la cadena de producción, distribución o comercialización conoce o ha debido conocer del defecto del producto que ha producido o puede producir un evento adverso contra la vida, la salud o la seguridad de las personas. Ahora, no se trata de establecer casos taxativos o enunciativos al respecto. A mi parecer, conforme a lo estudiado, debe determinar el juzgador o autoridad de conocimiento si el miembro de la cadena tuvo o no conocimiento bajo los criterios del buen hombre de negocios y la diligencia calificada del profesional.

2. Debe regularse la información mínima a suministrar por el miembro de la cadena a la autoridad administrativa, dentro de la que se debe exigir, sin limitarse, (a) el producto objeto del defecto -sus características, el lote o serie a la que pertenece, el tipo de defecto que presenta-, (b) los datos de los

11. Al momento de desarrollar este estudio fue dado a conocer por el Ministerio de Comercio, Industria y Turismo el Proyecto de Decreto reglamentario del art. 19 del EC. 
compradores del producto, (c) el riesgo que implica el defecto que tiene el producto, y (d) las medidas correctivas tomadas o que se tomarán por parte del miembro de la cadena.

3. En cuanto a las denominadas medidas correctivas, se considera que deben ser divididas en dos grandes categorías: (a) aquellas dirigidas a prevenir o evitar el nacimiento del daño y (b) aquellas encaminadas a minimizar las consecuencias lesivas del perjuicio. A partir de los anteriores grupos deberán también reglamentarse las acciones frente a los productos despachados así como a los no despachados.

En todo caso, debe resaltarse, dadas las razones teóricas expresadas en los títulos previos, que las medidas correctivas no deben ser taxativas y deben guiarse por un único principio: el de salvaguardar la vida, la salud y seguridad de las personas y, particularmente, de los consumidores de los productos objeto de defecto.

4. Todas las actuaciones relacionadas con el deber de información, así como las implicaciones que en el marco de las medidas correctivas se generen, deben ser gratuitas para el consumidor.

5. La institución administrativa que se designe por vía reglamentaria para la recepción de la información debe ejercer un rol protagónico y tomar una posición activa de cara a la información suministrada con respecto al defecto del producto. De manera que ante el eventual incumplimiento o el incumplimiento parcial del deber por parte del miembro de la cadena, además de sancionarlo, tenga las herramientas suficientes para evitar o minimizar los daños que se puedan causar. En definitiva, la salud, la seguridad y la vida de las personas son derecho de interés público y general.

6. Por último, pero sumamente importante: es necesario que se reglamenten las implicaciones del cumplimiento del deber de información, evasión y mitigación del daño de que trata el art. 19 y, en especial, su parágrafo, dentro del régimen de la responsabilidad por productos defectuosos.

\section{CONCLUSIONES}

Con todo lo analizado, es dable enlistar las siguientes conclusiones generales:

i. El art. 19 del EC es una manifestación del principio de la buena fe objetiva, particularmente de los deberes secundarios o colaterales de conducta -información, evasión y mitigación del daño-. No solo ello, el art. 19 es fruto de la concepción preventiva de la máxima del derecho de daños: alterum non laedere.

ii. En razón de dicho entendimiento, el art. 19 del EC tiene una doble repercusión: (a) administrativa, en el entendido que establece una obligación de información frente al Esta- 
do, cuyo incumplimiento acarrea sanciones, dirigida a que el miembro de la cadena de producción, distribución o comercialización comunique de la existencia de un defecto en sus productos, que puede generar daños a las personas. No solo ello, que con fundamento en esa información, el miembro de la cadena tome las medidas correctivas correspondientes.

De otra parte, el art. 19 del EC ostenta (b) una función en el campo de la responsabilidad por productos defectuosos. A su amparo, el miembro de la cadena debe informar a sus consumidores y al público en general de la existencia del defecto y, en caso de la distribución del producto con o sin existencia de perjuicios, evitar o aminorar las consecuencias lesivas del daño.

iii. Desde el derecho comparado, el art. 19 del EC debería ubicarse dentro de las reglas referentes a la seguridad y protección de la salud del consumidor, que por demás adeuda el legislador colombiano.

Ahora, su asiento dentro del título relativo a la responsabilidad por productos defectuosos de la Ley 1480 de 2011 hace aún más manifiestas sus repercusiones dentro del citado régimen de responsabilidad, por lo que dicho efecto debe ser materia de reglamentación.

iv. Adicionalmente, son asuntos que deben reglamentarse: la información mínima que debe remitirse a la administración; las me- didas correctivas -que en mi concepto no deben ser taxativas y deberían ser divididas en dos grupos: aquellas dirigidas a prevenir o evitar el nacimiento del daño y aquellas encaminadas a minimizar las consecuencias lesivas del perjuicio-; las sanciones, entre otras no menos importantes.

Referencias

1. Agencia Española de Medicamentos y Productos Sanitarios. (2015). Información para las notificaciones de sospechas de reacciones adversas a medicamentos por parte de profesionales sanitarios. Obtenido de aemps.gov: <http://www.aemps.gob. es/vigilancia/medicamentosUsoHumano/ SEFV-H/NRA-SEFV-H/notificaSospechasRAM-profSanitarios.htm> [en línea]

2. Benítez Caorsi, J. J. (2006). La obligación de minimizar el daño. Revista de Responsabilidad Civil y Seguros (6), 11-23.

3. Bernal Fandiño, M. (2012). El deber de coherencia en el derecho colombiano de los contratos. Bogotá: Pontificia Universidad Javeriana.

4. Betti, E. (1969). Teoría general de las obligaciones (t. I). Madrid: Editorial Revista de Derecho Privado.

5. Corte Constitucional de Colombia. Sentencia C-1194 de 2008 (M. P.: Rodrigo Escobar Gil; diciembre 3 de 2008). 
6. Corte Constitucional de Colombia. Sentencia C-1008 de 2010 (M. P.: Luis Ernesto Vargas Silva; diciembre 9 de 2010).

7. Corte Suprema de Justicia, Sala de Casación Civil. Gaceta Judicial LXXII, 101. (Mayo 12 de 1952).

8. Corte Suprema de Justicia. Sala de Casación Civil y Agraria. Exp. 5372 (M. P.: Jorge Antonio Castillo Rugeles; agosto 9 de 2000).

9. Corte Suprema de Justicia. Sala de Casación Civil. Exp. 6146 (M. P.: Carlos Ignacio Jaramillo; agosto 2 de 2001).

10. Corte Suprema de Justicia. Sala de Casación Civil. Exp. 7069 (M. P.: Carlos Ignacio Jaramillo; septiembre 30 de 2002).

11. Corte Suprema de Justicia. Sala de Casación Civil. Exp.1997-9124 02 (M. P.: Pedro Octavio Munar Cadena; febrero 2 de 2005).

12. Corte Suprema de Justicia. Sala de Casación Civil. Exp. 254.01 (M. P.: Pedro Octavio Munar Cadena; agosto 9 de 2007).

13. Corte Suprema de Justicia. Sala de Casación Civil. Exp.: 05001-3103-009-200100263-01 (M. P.: William Namén Vargas; octubre 19 de 2009).

14. Corte Suprema de Justicia Sala de Casación Civil. Exp. 05001-3103-010-2000-
00012-01 (M. P.: William Namén Vargas; diciembre 16 de 2010).

15. Corte Suprema de Justicia. Sala de Casación Civil. Exp. 11001-3103-040-200600537-01 (M. P.: William Namén Vargas; febrero 21 de 2012).

16. Cubides Camacho, J. (2008). Obligaciones. Bogotá: Pontificia Universidad Javeriana.

17. Decreto 3466 de 1982. [Presidencia de la República]. Por el cual se dictan normas relativas a la idoneidad, la calidad, las garantías, las marcas, las leyendas, las propagandas y la fijación pública de precios de bienes y servicios, la responsabilidad de sus productores, expendedores y proveedores, y se dictan otras disposiciones. (Antiguo Estatuto del Consumidor).

18. Chinchilla Imbett, C. A. (Julio-Diciembre de 2011). El deber de información contractual y sus límites. Revista de Derecho Privado, (21), 327-350.

19. De Ángel Yágüez, R. (2000). Responsabilidad por informar. En J. A. Moreno Martínez (Coord.), Perfiles de la responsabilidad civil en el nuevo milenio. Madrid: Dykinson.

20. De Gásperi, L. (1945). Tratado de las obligaciones. Parte general (Vol. I). Buenos Aires: Depalma.

21. De los Mozos, J. L. (1965). El principio de la buena fe. Barcelona: Casa Editorial Bosch. 
22. Díez-Picazo, L. (1977). El principio general de la buena fe. Madrid: Editorial Civitas.

23. Díez-Picazo, L. (2011). Fundamentos de Derecho Civil Patrimonial. T.V. La responsabilidad civil. Madrid: Editorial Civitas.

24. Domínguez Hidalgo, C. (2012). Deber de minimizar los daños de la víctima o del acreedor. En Responsabilidad civil, derecho de seguros y filosofía del derecho. Homenaje al profesor Javier Tamayo JaramiIlo. Medellín: Biblioteca Jurídica Diké.

25. Fuentes Guíñez, R. (2006). El deber de evitar y mitigar el daño. Revista de Derecho, Universidad de Concepción, (217-218).

26. Jaramillo Jaramillo, C. I. (2013). Los deberes de evitar y mitigar el daño. Funciones de la responsabilidad civil en el siglo XXI y trascendencia de la prevención. Bogotá: Temis/Pontificia Universidad Javeriana.

27. Larenz, K. (1958). Derecho de obligaciones (t. II). Madrid: Editorial Revista de Derecho Privado.

28. Le Tourneau, P. (2006). La responsabilidad civil profesional. Bogotá: Legis.

29. Ley 1480 de 2011. [Congreso de la República de Colombia]. Por medio de la cual se expide el Estatuto del Consumidor y se dictan otras disposiciones.
30. Mansfield, L. (2003). El concepto de la buena fe en los contratos. Revista de la Academia Colombiana de Jurisprudencia, (324).

31. Meruzzi, G. (2002). La Trattativa maliziosa. Padova: CEDAM.

32. Messineo, F. (1979). Manual de derecho civil y comercial (t. vI). Buenos Aires: Ediciones Jurídicas Europa-América.

33. Ordoqui Castilla, G. (2012). Buena fe contractual. Bogotá: Pontificia Universidad Javeriana/Grupo Editorial Ibáñez/Universidad Católica de Uruguay.

34. Planiol, M. y Ripert, J. (1940). Tratado práctico de derecho civil francés. Las obligaciones. Primera parte (t. vI). La Habana: Editorial Cultura S. A.

35. Richard, E. H. (1997). Fraccionamiento de la responsabilidad frente a consumidores y terceros a través de los contratos de colaboración. En C. A. Ghersi, Los derechos del hombre: daños y protección a la persona. Mendoza: Ediciones Jurídicas Cuyo.

36. Solarte Rodríguez, A. (2004). La buena fe contractual y los deberes secundarios de conducta. Vniversitas, 53 (108), 282-315.

37. Superintendencia de Industria y Comercio. Concepto 12-171565-4-0. Noviembre 22 de 2012. 
38. Superintendencia de Industria y Comercio. Concepto 12-196442-3-0. Diciembre 21 de 2012.

39. Trigo Represas, F. A. (2009). La buena fe y su relación con la responsabilidad civil. En M. R. Córdoba (Dir.), Tratado de la buena fe en el derecho, (t. I). Buenos Aires: La Ley.
40. Unión Europea. (6 de agosto de 2010). Directiva 2010/53/UE del Parlamento Europeo y del Consejo de 7 de julio de 2010, sobre normas de calidad y seguridad de los órganos humanos destinados al trasplante.

41. Zavala de González, M. (2004). Actuaciones por daños: prevenir, indemnizar, sancionar. Buenos Aires: Hammurabi. 